\title{
Prognostic Value of Biomarkers in Cardiac Allograft Vasculopathy following Heart Transplantation: A Literature Review
}

\author{
Shaghayegh Habibi ${ }^{a}$ Eiman Ghaffarpasand ${ }^{a}$ Fahimehalsadat Shojaei $^{a}$ \\ Mahda Alihashemi $^{\mathrm{a}}$ Farima Kahe $^{\mathrm{a}}$ Farbod Zahedi Tajrishi $^{\mathrm{b}}$ Gerald Chi $^{\mathrm{a}}$ \\ ${ }^{a}$ Division of Cardiovascular Medicine, Beth Israel Deaconess Medical Center, Harvard Medical School, Boston, MA, USA; \\ bTehran Heart Center, Tehran University of Medical Sciences, Tehran, Iran
}

\section{Keywords}

Allografts · Biomarkers · Heart transplantation · Prognosis ·

Vascular diseases

\begin{abstract}
Cardiac allograft vasculopathy (CAV), also known as cardiac transplant vasculopathy, is a major determinant of longterm survival among cardiac transplantation recipients. Histologically, CAV is featured by diffuse, concentric thickening of the vascular wall, and primarily affects large and small epicardial coronary arteries, intramyocardial arteries, and veins. Owing to graft denervation, CAV typically follows an insidious course, and patients may not experience classic angina symptoms but instead present with progressive heart failure or ventricular arrhythmias. Recent studies on biomarkers have furthered the knowledge concerning the prediction and prognosis of CAV. Given its association with metabolic, thrombotic, inflammatory, and immunologic markers, CAV is likely to represent a complex multifactorial process that involves both immune-mediated and non-immune-mediated pathways. In order to identify the high-risk patients that would benefit from early intervention, future research is warranted to examine the usefulness of a biomarker panel in $\mathrm{CAV}$ risk stratification.

(c) 2020 S. Karger AG, Basel
\end{abstract}

\section{Introduction}

Cardiac allograft vasculopathy (CAV), also known as cardiac transplant vasculopathy, is caused by progressive thickening of the coronary vascular wall with narrowing of the vessel lumen after heart transplantation, which leads to blood flow impairment and ischemic consequences such as graft failure, arrhythmias, and sudden death. CAV is a major determinant of long-term survival among cardiac transplantation recipients [1]. Given its association with metabolic, thrombotic, inflammatory, and immunologic markers, CAV is likely to represent a complex multifactorial process that involves both immune-mediated and non-immune-mediated pathways. Emerging literature points to the usefulness of biomarkers in predicting the outcome of CAV following heart transplantation. This review briefly summarizes the current knowledge of CAV and focuses on the discussion of available evidence on the prognostic value of biomarkers.

\section{Definition}

In the historical literature, the definition of CAV has been equivocal. CAV used to be defined as coronary luminal irregularity or stenosis from 30 to $70 \%$. Until 2010,

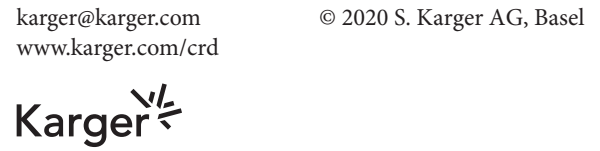


Table 1. Definition and grading of cardiac allograft vasculopathy (CAV) by the 2010 ISHLT consensus statement [2]

\begin{tabular}{|c|c|c|}
\hline Grade & Severity & Definition \\
\hline $\mathrm{CAV}_{0}$ & Not significant & No detectable angiographic lesion \\
\hline $\mathrm{CAV}_{2}$ & Moderate & $\begin{array}{l}\text { Left main stenosis }<50 \% \text {; or a single primary vessel stenosis } \geq 70 \% \text {, or isolated branch stenosis } \geq 70 \% \text { in } \\
\text { branches of } 2 \text { systems, without allograft dysfunction }\end{array}$ \\
\hline $\mathrm{CAV}_{3}$ & Severe & $\begin{array}{l}\text { Left main stenosis } \geq 50 \% \text {, or stenosis of } 2 \text { or more primary vessels } \geq 70 \% \text {, or isolated branch stenosis } \geq 70 \% \text { in } \\
\text { all } 3 \text { systems; or ISHLT CAV } \mathrm{V}_{1} \text { or ISHLT CAV } \mathrm{C}_{2} \text { with allograft dysfunction } \\
\text { Note: Allograft dysfunction is defined as left-ventricular ejection fraction } \leq 45 \% \text { (usually in the presence of } \\
\text { regional wall motion abnormalities) or evidence of significant restrictive physiology; restrictive cardiac } \\
\text { allograft physiology is defined as symptomatic heart failure with echocardiographic E/A velocity ratio }>2 \\
\text { ( }>1.5 \text { in children), shortened isovolumetric relaxation time }(<60 \mathrm{~ms} \text { ), shortened deceleration time }(<150 \\
\text { ms), or restrictive hemodynamic values (right atrial pressure }>12 \mathrm{~mm} \mathrm{Hg} \text {, pulmonary capillary wedge } \\
\left.\text { pressure }>25 \mathrm{~mm} \mathrm{Hg} \text {, or cardiac index }<2 \mathrm{~L} / \mathrm{min} / \mathrm{m}^{2}\right)\end{array}$ \\
\hline
\end{tabular}

the International Society of Heart and Lung Transplantation (ISHLT) released a consensus statement to unify its nomenclature [2]. The ISHLT nomenclature is based on the severity of maximum luminal stenosis (determined by coronary angiography) in conjunction with the evidence of allograft dysfunction (determined by ejection fraction) or significant restrictive physiology (determined by echocardiographic and hemodynamic parameters). Accordingly, CAV can be classified into 4 categories: normal or nonsignificant $\mathrm{CAV}\left(\mathrm{CAV}_{0}\right)$, mild $\mathrm{CAV}\left(\mathrm{CAV}_{1}\right)$, moderate $\mathrm{CAV}\left(\mathrm{CAV}_{2}\right)$, or severe $\mathrm{CAV}\left(\mathrm{CAV}_{3}\right)$ (Table 1).

\section{Epidemiology}

There has been a downward trend in the incidence of CAV. Regardless of disease severity, CAV is detected in $8 \%$ of patients by 1 year, $23-29 \%$ by 5 years, and $50 \%$ by 10 years following transplantation $[3,4]$. A study aiming to evaluate the prevalence of clinically important lesions has revealed that the frequency of severe coronary disease is only $7 \% 5$ years after heart transplantation [5].

\section{Clinical Presentation}

As a result of denervation after cardiac transplantation, typical anginal pain associated with myocardial ischemia or infarction may not be experienced by patients with CAV. Therefore, most CAV patients remain asymptomatic or have unspecific chest discomfort or atypical symptoms until the development of ventricular arrhythmias, congestive heart failure, or sudden death [6]. The study by Gao et al. [7] indicates that weakness, dyspnea, and palpitations were the most common explicit CAV symptoms in 22 cardiac transplant patients who experienced 25 documented myocardial infarctions.

\section{Histology and Pathophysiology}

Unlike atherosclerosis, CAV diffusively affects the coronary vasculature. On histological examination, CAV is characterized by a concentric thickening of the vascular wall combined with intima and smooth muscle hypertrophy, and primarily affects large and small epicardial coronary arteries, as well as intramyocardial arteries and veins. The exact pathogenesis of CAV remains unclear but most likely involves vascular damage due to both immunologic and nonimmunologic processes. The immunologic hypothesis is supported by the diffuse involvement of the donor's rather than recipient's vasculatures, animal CAV models with histocompatibility mismatch, and lack of vasculopathy in isografts [6]. It has been postulated that both cellular and humoral immune responses of the recipient are directed against the graft. Specifically, the immune response of the recipient can be triggered via a direct or an indirect pathway. In the direct pathway, recipient $\mathrm{T}$ cells are activated after recognition of allogeneic major histocompatibility complexes (MHCs) of donor 
antigen-presenting cells [8]. The indirect pathway is triggered when the host antigen-presenting cells, mainly dendritic cells, process and present MHC-derived alloantigens from the donor's heart tissue, leading to the production of donor-specific antibodies, inflammatory cytokines, and endothelial damage via activation of $\mathrm{B}$ and $\mathrm{T}$ cells [9]. Antibodies such as the anti-human leukocyte antigen (HLA) and anti-endothelium antibodies may also activate the complement system, which may engage the vascular endothelial cells of the transplanted heart, leading to CAV, graft rejection, and even death [10]. Damaged endothelial cells present MHC class II antigens, which in turn activate CD4+ T cells. The immune reaction may progress even further with increased expression of the intercellular cell adhesion molecule-1, vascular cell adhesion molecule-1, and $\mathrm{P}$ selectin on the surface of transplanted heart endothelium. Notably, many of these mediators in the immunologic pathway are demonstrated to be predictive of vasculopathy in cardiac transplant recipients.

Nonimmunologic processes are less described in the literature, and include endothelial destruction and nonspecific coagulation disturbances that either aggravate or interact with immunologic processes. Both immunologic and nonimmunologic pathways result in subsequent endothelial injury as well as activation of endothelium, proliferation of smooth muscle cells, and abnormal deposition of extracellular matrix proteins within the vessel walls. Consequently, the disruption of endothelial cell homeostasis is a hallmark of concentric intimal hypertrophy, which is the cardinal histopathologic feature of CAV. During this process, endothelial progenitor cells are decreased, and smooth muscle progenitor cells are increased, both reflecting the role of endothelium allogenicity in CAV vascular biology $[11,12]$. Eventually, intimal proliferative changes result in luminal stenosis and occlusion.

\section{Risk Factors}

Analyses of risk factors in heart transplant recipients with CAV have identified both alloantigen-dependent and -independent factors. Alloantigen-dependent risk factors for CAV include the number of HLA mismatches, the number of previous rejection episodes, and their duration and time of onset after transplantation. Alloantigen-independent risk factors include older donor age, sex, hyperhomocysteinemia, cytomegalovirus (CMV) infection, ischemia/reperfusion injury, brain death, and conventional risk factors for atherosclerosis such as hypertension, hyperlipidemia, smoking, diabetes mellitus, and obesity [13]. In addition, risk factors for CAV in children include older donor age, older recipient age, donor cigarette use, recipient African-American race, transplant era, no induction therapy, history of retransplantation, rejection in the first year after heart transplant, and repeated episodes of cellular rejection $[14,15]$.

It is noteworthy that arterial changes in CAV and atherosclerosis share some common features. First, early lesions in both conditions may involve eccentric formation of a hyperplastic intima. Further, both CAV and atherosclerosis tend to spare the vessel media and are associated with adventitial inflammation. Finally, both processes are related to endothelial dysfunction in the form of inadequate vasodilation in response to acetylcholine. Interestingly, medical therapy for primary prevention in atherosclerosis has been shown to reduce the incidence of CAV, although the effect is modest [16].

\section{Screening and Diagnostic Imaging}

Due to the latent nature during the early disease trajectory, screening for CAV is suggested in heart transplant recipients through imaging and laboratory indices. Screening during the first 5 years after heart transplantation in patients with normal renal function (glomerular filtration rate $[\mathrm{GFR}] \geq 30-40 \mathrm{~mL} / \mathrm{min} / 1.73 \mathrm{~m}^{2}$ ) should be performed annually or biannually with coronary angiography to assess the development of CAV in patients with heart transplantation. For subjects with renal insufficiency $\left(\right.$ GFR $\left.<30-40 \mathrm{~mL} / \mathrm{min} / 1.73 \mathrm{~m}^{2}\right)$, it is suggested to receive annual dobutamine stress echocardiography. Individuals without CAV 3-5 years after heart transplantation, especially those with renal insufficiency, may undergo less frequent invasive evaluation such as annual dobutamine stress echocardiography [17].

Coronary angiography was the key diagnostic imaging for CAV before the development of intracoronary imaging. Although coronary angiography has certain limitations, the ISHLT still suggests angiography as a screening tool to grossly detect the presence of CAV. The main issue with coronary angiography is that only the vessel lumen but not the vessel wall can be opacified by the contrast media. Therefore, angiography cannot assess several $\mathrm{CAV}$-associated features such as vascular remodeling and vasodilation. Nevertheless, for individuals with evidence of CAV during the first 5 years after heart transplantation, annual coronary angiography is recommended if renal function permits. In pediatric patients with heart transplantation, the diagnostic study of choice is selective coronary angiography on an annually or biannually basis [17]. 

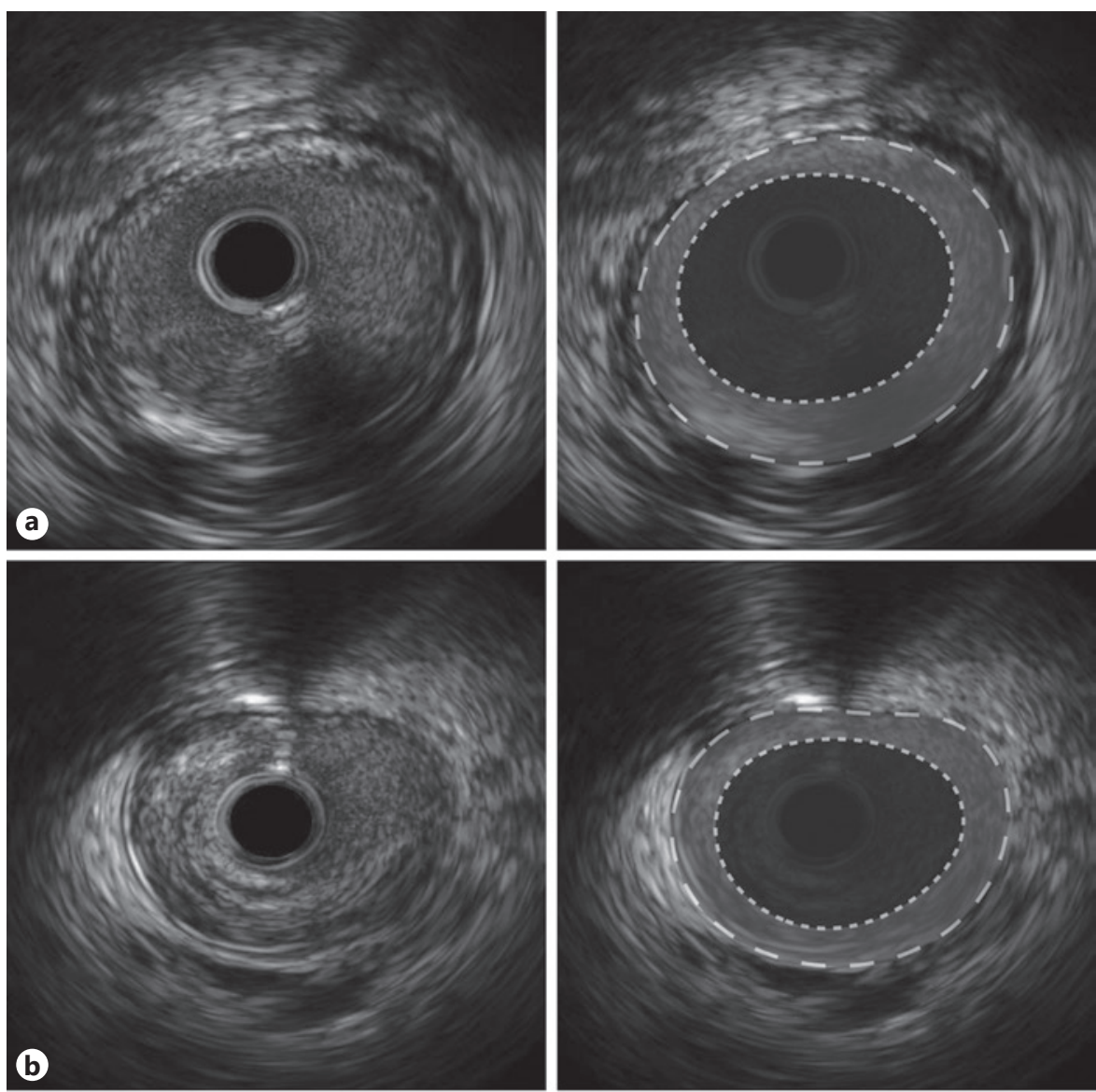

Fig. 1. Intravascular ultrasound of cardiac allograft vasculopathy in the distal left main artery (a) as well as the proximal (b) and middle (c) left anterior descending artery 1 year after heart transplantation, demonstrating a concentric pattern of intimal thickening with positive and negative remodeling and absence of calcification (image courtesy of Dr. Elias A. Sanidas, Laiko General Hospital, University of Athens Medical School).
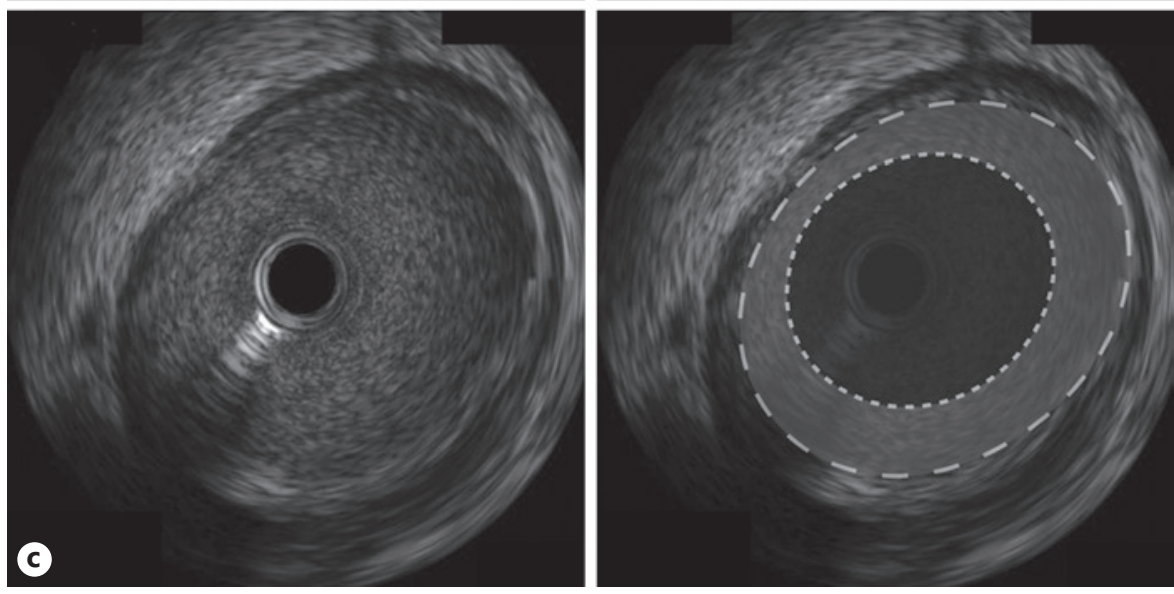

Intracoronary imaging such as intravascular ultrasound (IVUS) and optical coherence tomography (OCT) is useful in predicting CAV-related cardiovascular end points even in individuals with normal coronary angiography findings. The initial manifestations of CAV reside in the coronary wall. Intracoronary imaging is therefore more sensitive in the early detection of CAV than coronary angiography [2]. As the intima thickens, coronary vessels undergo compensatory dilatation to preserve the luminal area (i.e., Glagov remodeling) [18]. With disease progression, outward positive remodeling of coronary arteries is followed by inward negative remodeling and luminal narrowing [19]. IVUS allows for visualization of the vascular layers and can delineate the features of CAV including concentric thickening, positive and negative remodeling, and absence of calcification in the early stage 
(Fig. 1). IVUS in conjunction with coronary angiography 4-6 weeks and 1 year after heart transplantation is of prognostic and diagnostic value [20]. OCT allows for high-resolution characterization of the coronary arteries and may be useful in distinguishing between donortransmitted and transplant vascular endothelial disease [21]. However, the role of OCT in the diagnosis of CAV has not been comprehensively evaluated.

In patients who cannot tolerate invasive procedures, treadmill or dobutamine stress echocardiography along with myocardial perfusion imaging may be beneficial for diagnosing CAV [22]. Ultrafast computed tomography (CT), commonly used to detect calcifications in coronary vessels, may be considered as an investigational diagnostic modality for CAV. Coronary CT angiography may be considered as an alternative; however, its usefulness is limited by induced tachycardia during rest in patients with heart transplantation. For CAV patients who have undergone percutaneous coronary intervention (PCI), follow-up coronary angiography is recommended after 6 months regarding high rates of restenosis $[17,23]$.

In a study by Colvin-Adams et al. [24], perfusion magnetic resonance imaging (MRI) was used to detect CAV (defined as stenosis $\geq 25 \%$ in a major epicardial artery) and yielded a sensitivity of $41 \%$ and specificity of $74 \%$. Notably, there was a slight increase in sensitivity and a decrease in specificity with increased severity of CAV. Qualitative perfusion MRI is insensitive in the detection of CAV and therefore should not be used as a screening study. In contrast, quantitative assessments may enhance its ability for CAV detection and thus represent a more reliable noninvasive diagnostic tool.

Of note, CAV affects both the large epicardial coronary arteries and the microcirculation. Impaired myocardial perfusion associated with microvascular disease can be assessed by measuring coronary flow reserve (CFR) or index of microcirculatory resistance. CFR is a useful tool to evaluate the presence and severity of CAV, and it is particularly helpful for early detection of CAV in patients who do not present with visible angiographic narrowing. CFR is also recommended as an addition to dobutamine stress echocardiography to improve the accuracy of CAV assessment at centers with sufficient technical experience. Furthermore, the 2015 European Association of Cardiovascular Imaging recommendations suggest that CFR can be combined with stress echocardiography to improve its accuracy [25].

Coronary angiography combined with myocardial biopsy remains the standard approach for identifying chronic graft failure. Nevertheless, new alternative non-

Cardiac Allograft Vasculopathy

Biomarkers invasive procedures have also been introduced for this purpose. For instance, to characterize regional irregularities in myocardial function, left-ventricular high-energy phosphates can be utilized using in vivo proton magnetic resonance spectroscopy. Another example is the phosphocreatine/adenosine triphosphate ratio, which is considered as the most promising index for the assessment of myocardial metabolism. The use of these radiation-free procedures instead of coronary angiography for surveillance of heart transplant patients is particularly important because these patients are reportedly at an increased risk of malignancy potentially due to the cumulative effects of immunosuppression and radiation exposure. Approximately $14.1-15.6 \%$ of the 5 -year heart transplant survivors develop malignancies [26]. The incidence increases to roughly $50 \%$ at 15 years of follow-up, with skin cancers $(60 \%)$, solid tumors ( $35 \%)$, and posttransplant lymphoproliferative disease $(10-15 \%)$ as the most frequent malignancies [26]. Therefore, the use of radiationbased procedures should be reserved for assessing patients unsuitable for radiation-free techniques.

\section{Primary Prevention}

Prevention of CAV resides in the attenuation of adverse nonimmunologic and immunologic reactions. Several measures have been shown to be helpful in promoting posttransplant cardiac function and longevity. These include preventing endothelial injury at brain death, reducing cold ischemic time and its subsequent tissue damage, and improving myocardial preservation during graft storage and transportation [27]. Kevelaitis et al. [28] demonstrated that longer time of cold ischemia was associated with greater endothelial dysfunction in cardiac allografts. In contrast, addition of insulin to the blood perfusate during storage was demonstrated to improve functional and metabolic recovery during heart transplantation [27]. Several studies have indicated that adding bosentan or other endothelin antagonists to donorshed blood perfusion improves functional recovery of the myocardium and endothelium, and reduces the risk of CAV $[29,30]$.

\section{Management}

Immunosuppressive agents have been evaluated as the medical management of CAV in view of their ability to delay immunologic processes related to CAV. Methylprednisolone plus anti-thymocyte globulin treatment for 3 days, especially in the first year after heart transplantation, offers efficient protection against CAV; however, the regimen may be limited by complications such as se- 
vere infection and malignancy. While evidence suggests that both sirolimus and everolimus may prevent CAV, only sirolimus is used as treatment for vasculopathy [1, 31]. In patients with renal insufficiency, it is suggested to replace calcineurin inhibitors with sirolimus [32]. However, the Heart Save the Nephron trial showed high rates of grade IIIA heart transplantation rejection within 12 weeks after calcineurin inhibitor replacement with sirolimus [33]. Mycophenolate mofetil (MMF), another immunosuppressive agent, is also useful and has demonstrated greater efficacy in CAV treatment than azathioprine [34]. Most of the transplant centers adopt the combination of tacrolimus, MMF, along with corticosteroids as standard regimen for cardiac transplant recipients [35].

According to the ISHLT guidelines, various statins (e.g., pravastatin and simvastatin) have significant protective effects against vasculopathy in CAV $[17,36,37]$. Angiotensin-converting enzyme inhibitors are found to be effective in improving endothelial function and also promoting plaque regression in heart transplant patients [38]. Calcium channel blockers may also ameliorate plaque growth in the transplanted heart [39]. Of note, both have been postulated to exert synergistic therapeutic effects on CAV in heart transplant patients [40]. Antioxidant vitamins (e.g., vitamin $\mathrm{C}$ and vitamin $\mathrm{E}$ ) also showed some beneficial effects in transplanted heart vasculopathy via suppressing plaque formation [41].

In adult and pediatric patients with focal discrete single-vessel lesions, PCI with drug-eluting stents is recommended for short-term palliation. Cautions for PCI in patients with CAV include diffuse coronary lesions, distal vessel pruning, common comorbidities (e.g., diabetes mellitus and dyslipidemia), renal insufficiency, and history of in-stent restenosis episodes. PCI success rate has been estimated at $>92 \%$; however, $55 \%$ of patients would experience restenosis within the next 15 months [42]. In cases of moderate amenable vascular lesions, surgical revascularization is an alternative approach in highly selected patients. For more severe forms of CAV that are refractory to medical therapy, cardiac retransplantation may be considered if there are no contraindications.

\section{Prognostic Value of Biomarkers in CAV}

Key studies illustrating the predictive and prognostic value of biomarkers in CAV are outlined in Table 2. The discussion on biomarkers in different categories is presented below.

\section{Metabolic Profile}

Over the past decades, cholesterol and other lipid parameters have been linked to the risk of coronary atherosclerosis. It has been shown that total cholesterol, lowdensity lipoprotein (LDL) cholesterol, and triglyceride (TG) levels may increase several months following cardiac transplantation. In a study by Escobar et al. [43], cardiac transplant recipients with severe intimal thickness were found to have higher levels of total cholesterol, LDL cholesterol, and TG than recipients with mild or moderate intimal thickness. Additionally, Bae et al. [38] demonstrated that lowering the serum concentrations of lipids was associated with plaque regression and volumetric vascular remodeling in CAV as detected by three-dimensional IVUS. Another study by Raichlin et al. [44] found that a TG/high-density lipoprotein (HDL) cholesterol ratio was not only predictive of CAV risk but also associated with CAV severity. These findings suggest the hypothesis that hyperlipidemic patients may represent a high-risk subset among cardiac transplant recipients. More importantly, if dyslipidemia has a mechanistic role in the development of CAV, lipid-lowering interventions may be beneficial in preventing the process and improving the outcome of these patients.

\section{Inflammatory Markers}

Inflammation has been postulated to mediate the initiation and development of atherosclerotic plaques. Creactive protein (CRP) is an acute-phase reactant that increases in the context of acute or chronic inflammation. A study by Hognestad et al. [45] revealed that plasma levels of high-sensitivity CRP (hsCRP) were associated with angiographic evidence of CAV in a large cohort of heart transplantation recipients. Furthermore, a sustained increase in hsCRP was found to be an independent predictor of CAV development. CRP has been linked to complement activation, production of tissue factor by mononuclear cells, and impaired systemic endothelial vascular reactivity. The relationship between hsCRP and CAV may therefore be explained by these mechanisms. However, whether elevated CRP is involved in the causal pathway of CAV or is a bystander phenomenon needs to be clarified by future studies. Interestingly, in another study, the combination of CRP $>3 \mathrm{mg} / \mathrm{L}$ and TG/HDL $>3$ was associated with 2.8 -fold increased odds for major adverse cardiovascular events compared to patients with $\mathrm{CRP}<3 \mathrm{mg} / \mathrm{L}$ and TG/HDL $<3$ [44]. This suggests that a biomarker panel comprised of distinctive mechanistic pathways can be used to refine CAV risk prediction.
Habibi/Ghaffarpasand/Shojaei/ Alihashemi/Kahe/Zahedi Tajrishi/Chi 


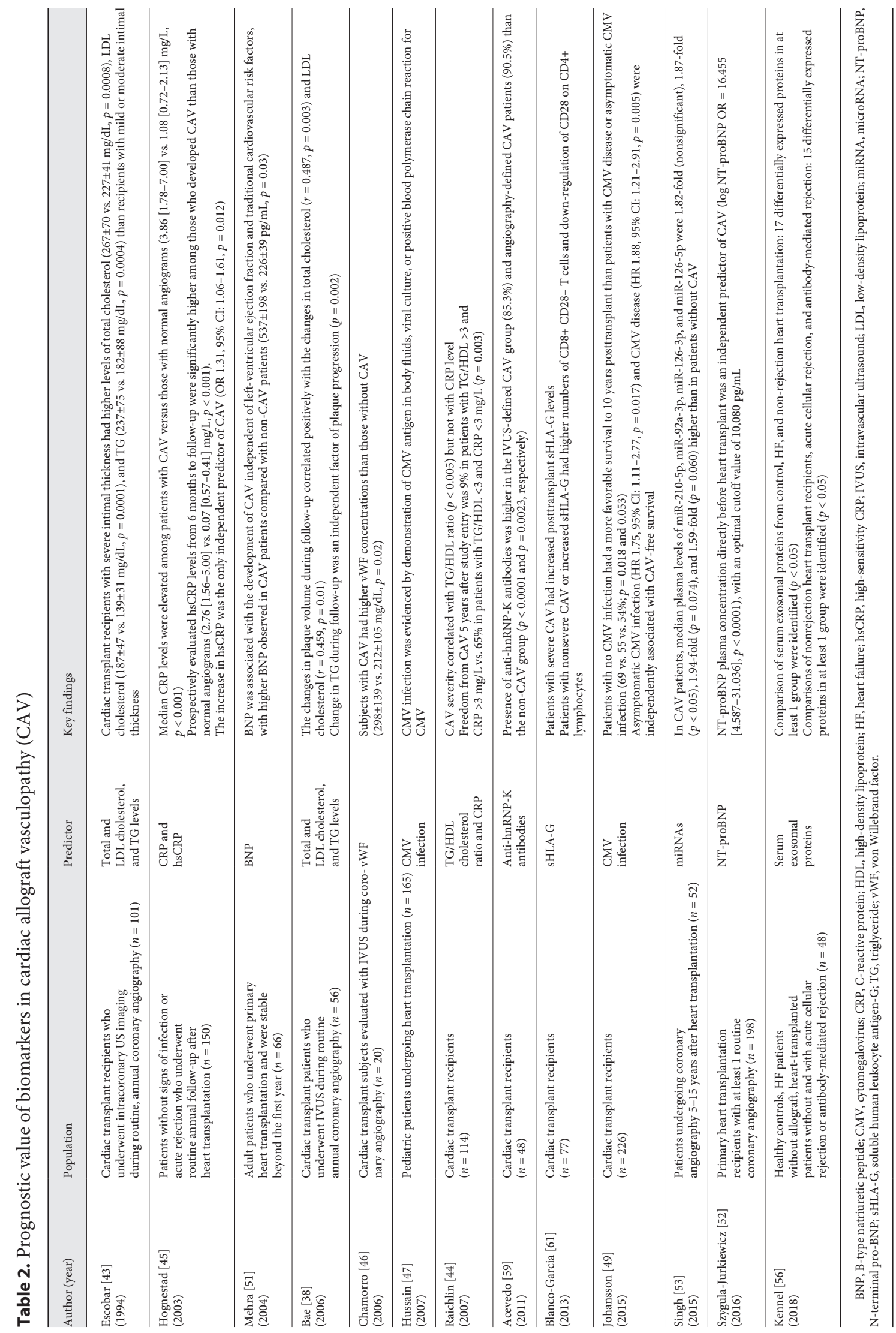




\section{Other Potential Biomarkers}

von Willebrand factor (vWF), a glycoprotein synthesized by the endothelium and platelets, is an essential mediator of platelet adhesion to the endothelium and thrombus formation. Previous studies have reported elevated levels of vWF in the circulation among cardiac transplant recipients. Chamorro et al. [46] demonstrated a significant difference in plasma levels of vWF between CAV and non-CAV patients. Elevated concentrations of vWF were considered to be released from injured endothelium from patients with CAV, which cannot be entirely attributable to a past medical history of atherosclerosis.

Hussain et al. [47] found that children who were positive for CMV before cardiac transplantation were at a greater risk of CAV and mortality even after adjustment for anti-CMV therapy. Patients who develop CMV infection after cardiac transplantation were also found to have more severe CAV than patients who were negative for active CMV infection [48]. Taken together, these findings suggest a role of CMV prophylaxis in this patient group with regard to its association with CAV risk and severity. Johansson et al. [49] also found that asymptomatic CMV infection and CMV disease were independent predictors with CAV-free survival. These results point to the potential value of close monitoring for CMV status and appropriate treatment for CMV infection.

B-type natriuretic peptide (BNP) is a neurohormone with various biological activities, including natriuresis, diuresis, and vasodilation [50]. BNP is initially synthesized as a prohormone and cleaved into the active C-terminal and inactive $\mathrm{N}$-terminal fragment ( $\mathrm{N}$-terminal pro-BNP; NT-proBNP) upon release into the circulation. In response to increased wall stress, BNP secreted by the ventricular myocardium may serve as a marker of cardiac allograft function. In a study by Mehra et al. [51], BNP was associated with the development of CAV independent of left-ventricular ejection fraction and conventional cardiovascular risk factors. Szygula-Jurkiewicz et al. [52] also reported NT-proBNP as an independent predictor for CAV. It is concluded that elevation in BNP or NTproBNP is not only a hemodynamic marker but also an indicator for the imbalance between ongoing allograft injury and repair.

MicroRNAs (miRNAs) are short, noncoding, singlestrand RNA sequences that negatively regulate gene expression at the posttranscriptional level by inhibiting translation or promoting degradation of target mRNAs. miRNAs circulate in remarkably stable forms in the blood and can be detected and serve as sensitive, specific biomarkers in various diseases. Several reports indicate that
miRNAs may play a role in endothelial homeostasis. A study by Singh et al. [53] investigated a candidate-based approach using circulating levels of endothelium-enriched miRNAs for the noninvasive diagnosis of CAV. It was shown that the levels of circulating endothelium-enriched miRNAs were higher in patients with than without CAV $[53,54]$.

Exosomes are membrane-derived, extracellular, lipid bilayer vesicles that play an important role in immune regulation and cell-to-cell communication. Immune cellderived exosomes are released constitutively from B cells, $\mathrm{T}$ cells, dendritic cells, and mast cells that are enhanced by $\mathrm{T}$-cell activation in immune responses. Several studies suggest that exosomes may be related to enhanced immune responses in cardiac allograft rejection and subsequent CAV development [55-57].

Heterogeneous nuclear ribonucleoprotein K (hnRNP$\mathrm{K}$ ) is a ubiquitous protein detected in the nucleus that accumulates in the cytoplasm under certain pathologic conditions. Its biologic function has been implicated in cell cycle progression as well as transcription, splicing, and translation processes [58]. Acevedo et al. [59] identified $\mathrm{hnRNP}-\mathrm{K}$ as a novel antigenic target from screening of a human coronary artery smooth muscle cell complementary DNA library with a CAV patient serum sample. In keeping with previous studies that demonstrated elevated hnRNP-K levels in smooth muscle cells of atherosclerotic vessels, this study found increased levels of anti-hnRNP$\mathrm{K}$ antibodies in patients with CAV, a disease featured by progressive intimal thickening secondary to smooth muscle proliferation.

HLA-G has been shown to have inhibitory effects on $\mathrm{T}$ cells, natural killer cells, and dendritic cells, and mediates immune tolerance by inhibiting graft rejection [60]. A study from Blanco-Garcia et al. [61] aimed to evaluate the role of soluble HLA-G (sHLA-G) in predicting the severity of CAV. The study revealed that patients with severe CAV had higher sHLA-G levels after transplantation. Additionally, patients with nonsevere CAV or an increased sHLA-G after transplantation had more $\mathrm{CD} 8+\mathrm{CD} 28-\mathrm{T}$ cells (indicative of $\mathrm{CD} 8+$ regulatory $\mathrm{T}$ cells) and downregulation of CD28 on CD4+ lymphocytes (indicative of tolerogenic helper $\mathrm{T}$ cells). In other words, sHLA-G may signify the emergence of regulatory and tolerogenic helper T cells, which are responsible for better graft acceptance. It was also concluded that quantification of sHLA-G during the first year after cardiac transplantation may be useful for identifying at-risk subsets with a more severe CAV trajectory which may benefit from early preventive measures.
Habibi/Ghaffarpasand/Shojaei/ Alihashemi/Kahe/Zahedi Tajrishi/Chi 


\section{Conclusion}

Given its association with metabolic, thrombotic, inflammatory, and immunologic markers, CAV may be a complex multifactorial process that develops insidiously following heart transplantation. Both immune-mediated and non-immune-mediated pathways have been implicated in the pathogenesis of CAV, as reflected by its independent association with biomarkers of various categories. In order to identify high-risk patients that would benefit from early intervention, future research is warranted to refine CAV risk stratification using biomarkers.

\section{Acknowledgment}

We are indebted to Dr. Elias A. Sanidas at the Laiko General Hospital, University of Athens Medical School, for providing intracoronary images of CAV. We thank the anonymous reviewers for the constructive comments and suggestions.

\section{Conflict of Interest Statement}

The work is not funded, and the authors declare no conflict of interests.

\section{References}

1 Skorić B, Čikeš M, Ljubas Maček J, Baričević Ž, Škorak I, Gašparović H, et al. Cardiac allograft vasculopathy: diagnosis, therapy, and prognosis. Croat Med J. 2014 Dec;55(6):562-76.

2 Mehra MR, Crespo-Leiro MG, Dipchand A, Ensminger SM, Hiemann NE, Kobashigawa JA, et al. International Society for Heart and Lung Transplantation working formulation of a standardized nomenclature for cardiac allograft vasculopathy-2010. J Heart Lung Transplant. 2010 Jul;29(7):717-27.

3 Lund LH, Edwards LB, Kucheryavaya AY, Dipchand AI, Benden C, Christie JD, et al.; International Society for Heart and Lung Transplantation. The Registry of the International Society for Heart and Lung Transplantation: Thirtieth Official Adult Heart Transplant Report-2013; focus theme: age. J Heart Lung Transplant. 2013 Oct;32(10):951-64.

4 Nagji AS, Hranjec T, Swenson BR, Kern JA, Bergin JD, Jones DR, et al. Donor age is associated with chronic allograft vasculopathy after adult heart transplantation: implications for donor allocation. Ann Thorac Surg. 2010 Jul;90(1):168-75.

5 Costanzo MR, Naftel DC, Pritzker MR, Heilman JK 3rd, Boehmer JP, Brozena SC, et al. Heart transplant coronary artery disease detected by coronary angiography: a multiinstitutional study of preoperative donor and recipient risk factors. Cardiac Transplant Research Database. J Heart Lung Transplant. 1998 Aug;17(8):744-53.

6 Schmauss D, Weis M. Cardiac allograft vasculopathy: recent developments. Circulation. 2008 Apr;117(16):2131-41.

7 Gao SZ, Schroeder JS, Hunt SA, Billingham ME, Valantine HA, Stinson EB. Acute myocardial infarction in cardiac transplant recipients. Am J Cardiol. 1989 Nov;64(18):1093-7.

8 van den Hoogen P, Huibers MM, Sluijter JP, de Weger RA. Cardiac allograft vasculopathy: a donor or recipient induced pathology? J Cardiovasc Transl Res. 2015 Mar;8(2):106-16.

9 Kaczmarek I, Deutsch MA, Kauke T, BeirasFernandez A, Schmoeckel M, Vicol C, et al.
Donor-specific HLA alloantibodies: longterm impact on cardiac allograft vasculopathy and mortality after heart transplant. Exp Clin Transplant. 2008 Sep;6(3):229-35.

10 Wehner J, Morrell CN, Reynolds T, Rodriguez ER, Baldwin WM 3rd. Antibody and complement in transplant vasculopathy. Circ Res. $2007 \mathrm{Feb}$; 100(2):191-203.

11 Simper D, Wang S, Deb A, Holmes D, McGregor C, Frantz R, et al. Endothelial progenitor cells are decreased in blood of cardiac allograft patients with vasculopathy and endothelial cells of noncardiac origin are enriched in transplant atherosclerosis. Circulation. 2003 Jul;108(2):143-9.

12 Schober A, Hristov M, Kofler S, Forbrig R, Löhr B, Heussen N, et al. CD34+CD140b+ cells and circulating CXCL12 correlate with the angiographically assessed severity of cardiac allograft vasculopathy. Eur Heart J. 2011 Feb;32(4):476-84.

13 Rahmani M, Cruz RP, Granville DJ, McManus BM. Allograft vasculopathy versus atherosclerosis. Circ Res. 2006 Oct;99(8):801-15.

14 Dipchand AI. Current state of pediatric cardiac transplantation. Ann Cardiothorac Surg. 2018 Jan;7(1):31-55.

15 Thrush PT, Hoffman TM. Pediatric heart transplantation-indications and outcomes in the current era. J Thorac Dis. 2014 Aug;6(8):1080-96.

16 Pober JS, Jane-wit D, Qin L, Tellides G. Interacting mechanisms in the pathogenesis of cardiac allograft vasculopathy. Arterioscler Thromb Vasc Biol. 2014 Aug;34(8):1609-14.

17 Costanzo MR, Dipchand A, Starling R, Anderson A, Chan M, Desai S, et al.; International Society of Heart and Lung Transplantation Guidelines. The International Society of Heart and Lung Transplantation Guidelines for the care of heart transplant recipients. J Heart Lung Transplant. 2010 Aug;29(8):914-56.

18 Lim TT, Liang DH, Botas J, Schroeder JS, Oesterle SN, Yeung AC. Role of compensatory enlargement and shrinkage in transplant coronary artery disease. Serial intravascular ultrasound study. Circulation. 1997 Feb;95(4):855-9.
19 Tsutsui H, Ziada KM, Schoenhagen P, Iyisoy A, Magyar WA, Crowe TD, et al. Lumen loss in transplant coronary artery disease is a biphasic process involving early intimal thickening and late constrictive remodeling: results from a 5-year serial intravascular ultrasound study. Circulation. 2001 Aug;104(6): 653-7.

20 Kobashigawa JA, Tobis JM, Starling RC, Tuzcu EM, Smith AL, Valantine HA, et al. Multicenter intravascular ultrasound validation study among heart transplant recipients: outcomes after five years. J Am Coll Cardiol. 2005 May;45(9):1532-7.

21 Shan P, Dong L, Maehara A, Nazif TM, Ali ZA, Rabbani LE, et al. Comparison between cardiac allograft vasculopathy and native coronary atherosclerosis by optical coherence tomography. Am J Cardiol. 2016 Apr;117(8): 1361-8.

22 Dipchand AI, Bharat W, Manlhiot C, Safi M, Lobach NE, McCrindle BW. A prospective study of dobutamine stress echocardiography for the assessment of cardiac allograft vasculopathy in pediatric heart transplant recipients. Pediatr Transplant. 2008 Aug;12(5):570-6.

23 Aqel RA, Wells BJ, Hage FG, Tallaj J, Benza R, Pamboukian S, et al. Re-stenosis after drugeluting stents in cardiac allograft vasculopathy. J Heart Lung Transplant. 2008 Jun;27(6): 610-5.

24 Colvin-Adams M, Petros S, Raveendran G, Missov E, Medina E, Wilson R. Qualitative perfusion cardiac magnetic resonance imaging lacks sensitivity in detecting cardiac allograft vasculopathy. Cardiol Res. 2011 Dec; 2(6):282-7.

25 Badano LP, Miglioranza MH, Edvardsen T, Colafranceschi AS, Muraru D, Bacal F, et al.; Document reviewers. European Association of Cardiovascular Imaging/Cardiovascular Imaging Department of the Brazilian Society of Cardiology recommendations for the use of cardiac imaging to assess and follow patients after heart transplantation. Eur Heart J Cardiovasc Imaging. 2015 Sep;16(9):919-48. 
26 Noor M, Shekhdar J, Banner NR. Radiation exposure after heart transplantation: trends and significance. J Heart Lung Transplant. 2011 Mar;30(3):309-14.

27 Ramzy D, Rao V, Brahm J, Miriuka S, Delgado D, Ross HJ. Cardiac allograft vasculopathy: a review. Can J Surg. 2005 Aug;48(4):319-27.

28 Kevelaitis E, Nyborg NC, Menasché P. Coronary endothelial dysfunction of isolated hearts subjected to prolonged cold storage: patterns and contributing factors. J Heart Lung Transplant. 1999 Mar;18(3):239-47.

29 Fedak PW, Rao V, Verma S, Ramzy D, Tumiati L, Miriuka S, et al. Combined endothelial and myocardial protection by endothelin antagonism enhances transplant allograft preservation. J Thorac Cardiovasc Surg. 2005 Feb;129(2):407-15.

30 Okada K, Nishida Y, Murakami H, Sugimoto I, Kosaka H, Morita H, et al. Role of endogenous endothelin in the development of graft arteriosclerosis in rat cardiac allografts: antiproliferative effects of bosentan, a nonselective endothelin receptor antagonist. Circulation. 1998 Jun;97(23):2346-51.

31 Lamich R, Ballester M, Martí V, Brossa V, Aymat R, Carrió I, et al. Efficacy of augmented immunosuppressive therapy for early vasculopathy in heart transplantation. J Am Coll Cardiol. 1998 Aug;32(2):413-9.

32 Raichlin E, Bae JH, Khalpey Z, Edwards BS, Kremers WK, Clavell AL, et al. Conversion to sirolimus as primary immunosuppression attenuates the progression of allograft vasculopathy after cardiac transplantation. Circulation. 2007 Dec;116(23):2726-33.

33 Hunt J, Bedánová $\mathrm{H}$, Starling RC, Rabágo G, Banner NR, Kobashigawa J, et al. 398: Premature termination of a prospective, open label, randomized, multicenter study of sirolimus to replace calcineurin inhibitors (CNI) in a standard care regimen of CNI, MMF and corticosteroids early after heart transplantation. J Heart Lung Transplant. 2007;26(2):S203.

34 Eisen HJ, Kobashigawa J, Keogh A, Bourge R, Renlund D, Mentzer R, et al.; Mycophenolate Mofetil Cardiac Study Investigators. Threeyear results of a randomized, double-blind, controlled trial of mycophenolate mofetil versus azathioprine in cardiac transplant recipients. J Heart Lung Transplant. 2005 May; 24(5):517-25.

35 Benatti RD, Taylor DO. Evolving concepts and treatment strategies for cardiac allograft vasculopathy. Curr Treat Options Cardiovasc Med. 2014 Jan;16(1):278.

36 Kobashigawa JA, Moriguchi JD, Laks H, Wener L, Hage A, Hamilton MA, et al. Tenyear follow-up of a randomized trial of pravastatin in heart transplant patients. J Heart Lung Transplant. 2005 Nov;24(11): 1736-40.

37 Wenke K, Meiser B, Thiery J, Nagel D, von Scheidt W, Krobot K, et al. Simvastatin initiated early after heart transplantation: 8-year prospective experience. Circulation. 2003 Jan; 107(1):93-7.
38 Bae JH, Rihal CS, Edwards BS, Kushwaha SS, Mathew V, Prasad A, et al. Association of angiotensin-converting enzyme inhibitors and serum lipids with plaque regression in cardiac allograft vasculopathy. Transplantation. 2006 Oct;82(8):1108-11.

39 Schroeder JS, Gao SZ, Alderman EL, Hunt SA, Johnstone I, Boothroyd DB, et al. A preliminary study of diltiazem in the prevention of coronary artery disease in heart-transplant recipients. $\mathrm{N}$ Engl J Med. 1993 Jan;328(3):164-70.

40 Erinc K, Yamani MH, Starling RC, Crowe T, Hobbs R, Bott-Silverman C, et al. The effect of combined Angiotensin-converting enzyme inhibition and calcium antagonism on allograft coronary vasculopathy validated by intravascular ultrasound. J Heart Lung Transplant. 2005 Aug;24(8):1033-8.

41 Fang JC, Kinlay S, Beltrame J, Hikiti H, Wainstein $M$, Behrendt $D$, et al. Effect of vitamins $\mathrm{C}$ and $\mathrm{E}$ on progression of transplant-associated arteriosclerosis: a randomised trial. Lancet. 2002 Mar;359(9312):1108-13.

42 Musci M, Loebe M, Wellnhofer E, Meyer R, Pasic M, Hummel M, et al. Coronary angioplasty, bypass surgery, and retransplantation in cardiac transplant patients with graft coronary disease. Thorac Cardiovasc Surg. 1998 Oct;46(5):268-74.

43 Escobar A, Ventura HO, Stapleton DD, Mehra MR, Ramee SR, Collins TJ, et al. Cardiac allograft vasculopathy assessed by intravascular ultrasonography and nonimmunologic risk factors. Am J Cardiol. 1994 Nov;74(10): 1042-6.

44 Raichlin ER, McConnell JP, Lerman A, Kremers WK, Edwards BS, Kushwaha SS, et al. Systemic inflammation and metabolic syndrome in cardiac allograft vasculopathy. J Heart Lung Transplant. 2007 Aug;26(8):826-33.

45 Hognestad A, Endresen K, Wergeland R, Stokke O, Geiran O, Holm T, et al. Plasma Creactive protein as a marker of cardiac allograft vasculopathy in heart transplant recipients. J Am Coll Cardiol. 2003 Aug;42(3):477-82.

46 Chamorro CI, Almenar L, Martínez-Dolz L, Reganon E, Sánchez-Lacuesta E, Villa P, et al. Usefulness of von Willebrand factor in cardiac allograft vasculopathy: preliminary experience. Transplant Proc. 2006 Oct;38(8):2566-8.

47 Hussain T, Burch M, Fenton MJ, Whitmore PM, Rees P, Elliott M, et al. Positive pretransplantation cytomegalovirus serology is a risk factor for cardiac allograft vasculopathy in children. Circulation. 2007 Apr;115(13): 1798-805.

48 Grattan MT, Moreno-Cabral CE, Starnes VA, Oyer PE, Stinson EB, Shumway NE. Cytomegalovirus infection is associated with cardiac allograft rejection and atherosclerosis. JAMA. 1989 Jun;261(24):3561-6.

49 Johansson I, Andersson R, Friman V, Selimovic N, Hanzen L, Nasic S, et al. Cytomegalovirus infection and disease reduce 10 -year cardiac allograft vasculopathy-free survival in heart transplant recipients. BMC Infect Dis. 2015 Dec;15(1):582.
50 Chi G, Januzzi JL, Korjian S, Daaboul Y, Goldhaber SZ, Hernandez AF, et al. N-terminal proB-type natriuretic peptide and the risk of stroke among patients hospitalized with acute heart failure: an APEX trial substudy. J Thromb Thrombolysis. 2017 Nov;44(4):457-65.

51 Mehra MR, Uber PA, Potluri S, Ventura HO, Scott RL, Park MH. Usefulness of an elevated B-type natriuretic peptide to predict allograft failure, cardiac allograft vasculopathy, and survival after heart transplantation. Am J Cardiol. 2004 Aug;94(4):454-8.

52 Szyguła-Jurkiewicz B, Zakliczyński M, Szczurek W, Skrzypek M, Gąsior M, Zembala M. Perioperative Risk Factors of Cardiac Allograft Vasculopathy in the Long-Term Follow-up. Transplant Proc. 2016 Jun;48(5):1736-41.

53 Singh N, Heggermont W, Fieuws S, Vanhaecke J, Van Cleemput J, De Geest B. Endothelium-enriched microRNAs as diagnostic biomarkers for cardiac allograft vasculopathy. J Heart Lung Transplant. 2015 Nov; 34(11):1376-84.

54 Neumann A, Napp LC, Kleeberger JA, Benecke N, Pfanne A, Haverich A, et al. MicroRNA 628-5p as a Novel Biomarker for Cardiac Allograft Vasculopathy. Transplantation. 2017 Jan;101(1):e26-33.

55 Sukma Dewi I, Celik S, Karlsson A, Hollander Z, Lam K, McManus JW, et al. Exosomal miR$142-3 p$ is increased during cardiac allograft rejection and augments vascular permeability through down-regulation of endothelial RAB11FIP2 expression. Cardiovasc Res. 2017 Apr;113(5):440-52.

56 Kennel PJ, Saha A, Maldonado DA, Givens R, Brunjes DL, Castillero E, et al. Serum exosomal protein profiling for the non-invasive detection of cardiac allograft rejection. J Heart Lung Transplant. 2018 Mar;37(3):409-17.

57 Sharma M, Liu W, Perincheri S, Gunasekaran M, Mohanakumar T. Exosomes expressing the self-antigens myosin and vimentin play an important role in syngeneic cardiac transplant rejection induced by antibodies to cardiac myosin. Am J Transplant. 2018 Jul;18(7): 1626-35.

58 Bomsztyk K, Denisenko O, Ostrowski J. hnRNP K: one protein multiple processes. BioEssays. 2004 Jun;26(6):629-38.

59 Acevedo MJ, Caro-Oleas JL, Álvarez-Márquez AJ, Sobrino JM, Lage-Gallé E, Aguilera I, et al. Antibodies against heterogeneous nuclear ribonucleoprotein $\mathrm{K}$ in patients with cardiac allograft vasculopathy. J Heart Lung Transplant. 2011 Sep;30(9):1051-9.

60 Rouas-Freiss N, Naji A, Durrbach A, Carosella ED. Tolerogenic functions of human leukocyte antigen G: from pregnancy to organ and cell transplantation. Transplantation. 2007 Jul;84(1 Suppl):S21-5

61 Blanco-García RM, López-Álvarez MR, Garrido IP, Salgado-Cecilia G, Campillo JA, Bolarín JM, et al. Post-transplant increase in soluble human leukocyte antigen-G associated with non-severe cardiac allograft vasculopathy. Hum Immunol. 2013 Mar;74(3):318-24.
Habibi/Ghaffarpasand/Shojaei/ Alihashemi/Kahe/Zahedi Tajrishi/Chi 